\title{
Determination of Success of Small and Medium Enterprises (SMEs) Supported by Agriculture Bank of the Province of Mazandaran in Iran
}

\author{
Leila Hassani ${ }^{1}$, Seyyed Mojtaba Mojaverian ${ }^{2}$ and Esmaeil Yasari ${ }^{3}$ \\ ${ }^{1}$ M.Sc student in Agricultural Economics, the Islamic Azad University, Arsanjan Branch, Iran \\ ${ }^{2}$ Associate professor, Sari Agriculture and Natural Resources University, Mazandaran, Iran \\ ${ }^{3}$ Department of Agricultural Science, Payame Noor University, Iran \\ Correspondence: Esmaeil Yasari, Department of Agricultural Science, Payame Noor University, Iran. E-mail: \\ e_yassari@yahoo.com
}

Received: April 26, 2012 Accepted: June 7, 2012 Online Published: August 8, 2012

doi:10.5539/jas.v4n9p230 URL: http://dx.doi.org/10.5539/jas.v4n9p230

\begin{abstract}
The SMEs Project was introduced as the third job creation project by the government; and it has been implemented in recent years. In this study, we have dealt with the factors influencing the success of the Small and Medium Enterprises (SMEs) that have received quick returns facilities from the Agriculture Bank of Mazandaran, Iran. The data in this research is documentary and includes 181 enterprises. The Logit model was used to determine the success of these SMEs in Iran. In this study, arrears installments of bank credit as a measure of success for SMEs were considered. Results show previous experience, investment timing and enterprises size had significant statistical effect on the success probability of SMEs. Taking the results obtained into consideration, it is suggested that the location and the feasibility of each project, the experience of the executive, and the size of the project (with respect to the credits needed), be taken into consideration by the officials of the Bank before the project is approved. The JEL classification System: L 25, C 21, G 21.
\end{abstract}

Keywords: SME, Logit, the Agriculture Bank, the province of Mazandaran

\section{Introduction}

Human resources form the main wealth of every nation and determine the trend of its socio-economic development (Kazemipour, 2006). Many years, unemployment is considered as one of the most economic and social problems in Iran. Recently the government executes the small and medium enterprises project (in Iran it is known as the firms of returns early) for dealing with this problem. In Iran, SMEs, are defined which have fewer than 50 workers.

The SMEs (firms return soon) project has met with positive and negative reactions in Iran. proponents argue some advantages such as low-cost job, higher productivity, and capital formation. Its critics point to the diversion of the facilities from the goals of the projects, the inflationary effects of the projects, the reduction in the ability of the Bank in extending credit to larger enterprises, and the lack of careful evaluation of the projects by the experts of the bank. The study by Ceranic et al. (2009) on the development of SMEs in Serbia led to the conclusion that the success or failure of SMEs depend on their size and on the type of their activity. Chung (2006) carried out research on the performance of SMEs in South Korea with respect to efficiency and productivity, and found that the productivity index of SMEs having fewer than 50 employees exhibited a higher growth rate than that of the larger SMEs; and the improvement in the production and in the productivity of the firms with a capital of less than a billion (dollars) was greater compared to firms which had more capital.

The research conducted by Broersma and Gautier (1997) indicated that small firms enjoyed higher and more stable job creation than large firms. Bilsen and Konings (1998) was centered on the study of job creation and destruction in Bulgaria, Poland, and Romania; and it showed that the age of a firm and its size negatively influenced the growth of job creation in the firm. Hassanpour and Aghashiri (2011) evaluated 28 poultry farms in the province of Kohkiloyeh and Boirahmad and showed that there was a direct and meaningful relationship between the level of education of the executives (and also that of the employees) and the degree of success of these farms at the 5\% probability level. Rezvani (2011) used the data related to 30 provinces (and also the descriptive statistical method) and showed that there was a significant correlation $(\mathrm{r}=0.522)$ between the bank 
credits granted and the level of job creation by the functioning SMEs. Jamsheedloo, Ma-afi, and Rassouli (2011) pointed out that the monetary, marketing, technical, organizational, and internal problems of the SMEs were responsible for their failure. Results obtained in the study conducted by Zeraatkeesh and Foroughi (2011) indicated that among the most important problems faced by SMEs engaged in trout culture in the province of Kohkiloyeh and Boirahmad were the lack of processing and packaging industries, of cold storage houses, of food production industries (secondary industries), of knowledge regarding the prevailing market conditions, of insufficient funds, and of trout fry farms. Zarenezhad and Ebrahimi (2011) estimated that the degree of deviation of the SMEs from their original goals for the whole country was about 37.65 percent; and showed that there was a positive correlation between the level of granted facilities and the number of jobs created, while the degree of deviation from the original goals of the SMEs and the level of facilities granted to them exhibited a negative correlation.

\section{Materials and Methods}

The data in this research is documentary and were obtained from the information available at the office supervising the branches of the agricultural Bank in the cities of the province of Mazandaran, at all the central credit granting branches (the credit and debt collection units) of the Agriculture Bank situated in the cities of the province, at the Projects and Plans office of the Agricultural Jihad Organization of the province, and at the General Office of Labor and Social Affairs of the province of Mazandaran. The statistical population included all the SMEs (1805 units) that had been referred to all the branches of the Agriculture Bank by the Agricultural Jihad Organization of the province and had received facilities between the years 2005 to 2009. From among these 1805 units, 181 were selected at random. The method used in this study is an econometric model (the Logit Model); and the dependent variable is the success or failure of the SMEs. The classification of the SMEs into successful and unsuccessful ones was a relative one since no definitive definition has been offered for the success or failure of SMEs in the available references. However, the following items can be used to infer the success or failure of the SMEs: Those SMEs are considered as unsuccessful that

1) had closed down at the time this study was carried out (the absolute and actual meaning of failure)

2) their present activities have deviated from those envisioned in the projects (failure in the policy sense)

3) are in arrears with installments and cannot not pay back their debts (failure in the banking sense)

4) have not enjoyed the expected profits and do not receive enough revenues from the projects to pay back their debts (even if they are not in arrears with the installments and pay their installments with revenues obtained outside of the projects) (failure in the financial sense)

5) their executives are unsatisfied with the investments they have made, because they think they have missed out on better opportunities (failure in the economic sense)

As can be seen from the definitions offered above, it is not possible to have a definitive classification of the projects into successful and unsuccessful ones. In this research, we regarded those SMEs successful that could use revenues or profits received from the projects to pay their installments (item 3).

The dependent variable in our study is existence or nonexistence unpaid installments. The explanatory variables included the managerial variables (experience in the activity carried out in the project, the level of education, and age), the economic variables (the size of the project, the annual credit granted per member of the work force employed in the SME), and the time and place variables (the location of the project, the time the project started). The model we used was as follows:

$$
\begin{aligned}
\mathrm{GH}_{\mathrm{i}}=\alpha_{0}+ & \alpha_{1} \text { HUSBANDRY }_{\mathrm{i}}+\alpha_{2} \text { AGE }_{\mathrm{i}}+\alpha_{3} \text { EXPERIENCE }_{\mathrm{i}}+\alpha_{4} \text { CREDIT/LABOR }_{\mathrm{i}}+\alpha_{5} \text { SIZE }_{\mathrm{i}}+ \\
& \alpha_{6} \text { CONTRIBUTION }_{\mathrm{i}}+\alpha_{7} \text { EDUCATION }_{\mathrm{i}}+\alpha_{8} \text { TIME }_{\mathrm{i}}+\alpha_{9} \text { LOCATION }_{\mathrm{i}}+\epsilon_{1}
\end{aligned}
$$

In the above function, GH indicates the SME is in arrears with the installments (represented with the code zero), or is not (represented with the code 1); HUSBANDRY is a dummy variable related to the type of activity (with husbandry given the code 1 and other activities the code zero); CREDIT/LABOR shows the level of annual credit granted per member of the work force employed in the SME; EDUCATION is a dummy variable representing the level of education (with the code 1 given to those with a university degree and zero to those not having a university degree); EXPERIENCE indicates the previous experience of the executive in months; Age refers to the age of the executive (in year); LOCATION is a Dummy variable indicating the place the project is implemented (with the cities in the central part of the province receiving the code 1, and those in the western or eastern parts given the code zero); CONTRIBUTION signifies the continuity of the activity of the SMEs (those 
closed down at the time the study was carried out receiving the code zero, and those active at that time given the code 1); TIME shows the time the contract was signed (with the contracts signed in 2006 or earlier receiving the code 1, and the more recent ones, those signed in 2006 or later, given the code zero); and SIZE indicates the size of the project (in this study, size refers to the level of the facilities received by the SMEs). To obtain this level of facilities, the mean of the facilities received by similar projects was calculated and the SMEs which had been granted a level of facilities lower than this average were given the code zero, while those which had received a level of facilities higher than this average received the code 1).

\section{Results}

The results of the analysis show that, the central part of the Mazandran province (Babol, Amol, and Sari) have received a bigger share of the granted facilities (more than 60\%), while the coastal cities (Babolsar, Noshahr, Chalous, Nour and Mahmoodabad) have shown less enthusiasm for these projects (probably because they have fewer citizens, do not have access to Sari the capital city of the province, etc.)

Results obtained showed that the increase in the facilities granted by the Bank caused a rise in the percentage of outstanding installments. Therefore, the smaller projects (here, meaning the projects which had received less facilities) were more successful. The time of the signing of the contract is another factor affecting the success of the SMEs because, due to the inflation existing in the country, the cost of constructing the older units (and the total expenses of getting the projects started) were less, and hence these older units are more likely to succeed and make enough profits in the cutthroat competition prevalent in the market (and, therefore, they have a smaller share of outstanding installments). The choice of suitable locations for the projects is another factor contributing to the success of the SMEs. The type of activity influences the success of SMEs. If facilities are granted to one type of activity, this will lead to competition in the market and bring about the failure of the SMEs. In between 181 Enterprises surveyed, about 45 percent of firms have without payments are backward. Among various activities, Animal husbandry activities has the highest and beekeeping has the lowest Unpaid installments rate (refer to Diagram 1).

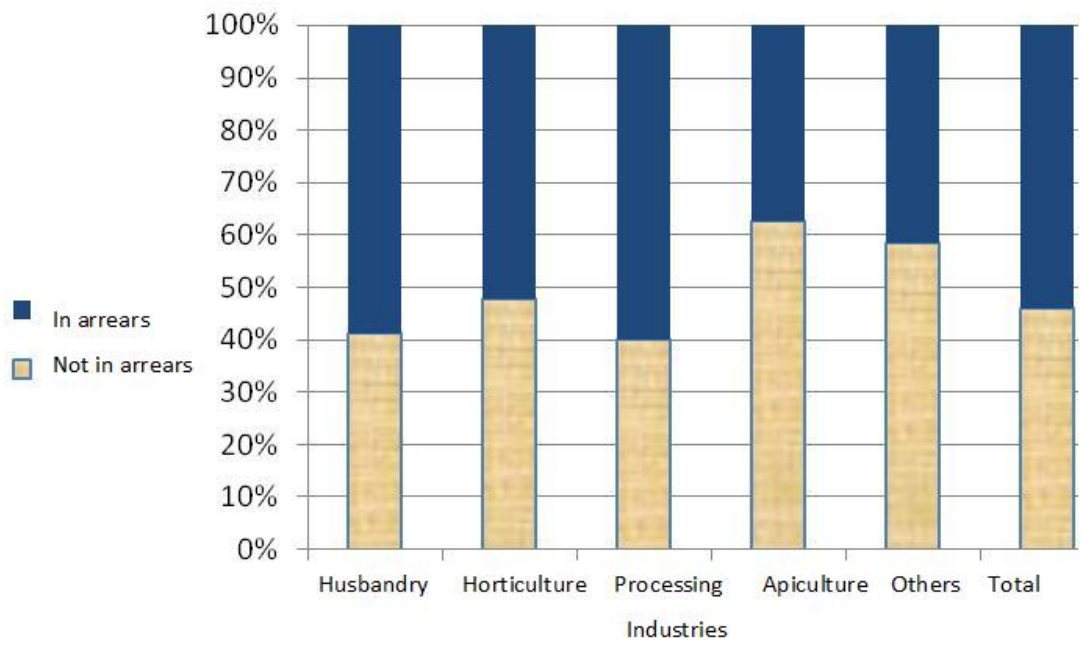

Diagram 1. Outstanding installments with respect to type of activity

Annual facilities granted per member of the work force of the SMEs also influenced the ability to pay back outstanding installments. Tables 1 and 2 show the relative frequencies of the variables employed. The greater this relative frequency, or the Coefficient of variation in the variables, is more appropriate for applying our logit model. 
Table 1. Coefficient of changes in the quantitative variables

\begin{tabular}{llllll}
\hline Variable & Average & Standard deviation & Coefficient of change & Minimum & Maximum \\
\hline Annual credits & 169.93 & 120.4 & $70.8 \%$ & 13 & 1199 \\
Experience of the executive & 119.6 & 103.7 & $115.3 \%$ & 2 & 600 \\
Size of the project & 862.2 & 145.9 & $59 \%$ & 18 & 11000 \\
Age of the executive & 49.8 & 23.9 & $208.3 \%$ & 27 & 78 \\
\hline
\end{tabular}

Source: Results obtained from the research

Table 2. The relative frequency of the qualitative variables

\begin{tabular}{lll}
\hline Variable & Frequency & Relative frequency \\
\hline $\begin{array}{l}\text { Type of activity } \\
\begin{array}{l}\text { Level of education } \\
\text { (higher education) }\end{array}\end{array}$ & 67 & $37 \%$ \\
$\begin{array}{l}\text { Time of signing the contract } \\
\text { (2006 or earlier) }\end{array}$ & 114 & $63 \%$ \\
$\begin{array}{l}\text { Location of the activity } \\
\text { (capital city of the province) }\end{array}$ & 128 & $70.7 \%$ \\
Continuity of the activity (active) & 169 & $93 \%$ \\
\hline
\end{tabular}

Source: Results obtained from the research

The Logit regression model was employed to investigate the effects of the various variables on the SMEs being in arrears with their installments or not (results obtained are presented in Table 3). It can be inferred from this table that from among the 9 variables entered into the model only the type of activity, the age of the executive, the previous experience of the executive in the activities related to the project, the time of the signing of the contract, the location of the project, and the annual facilities granted per member of the work force, significantly influence the ability to pay back the installments.

Since husbandry had a greater relative frequency than other types of activity, it was separated from the rest of the activities through the use of a Dummy variable. The results of the estimate show that this activity has a positive effect on outstanding installments. Government removed the farm subsidies in the last year. This policy led to higher cost prices of agricultural production. Between agriculture Activities, animal husbandry were more be affected by this policy. In contrast, government, for maintaining food security, will inhibit the growth of the sales price. Therefore the producers' ability, especially husbandry, reduced for paying installments. On the average, greater credits granted led to more outstanding installments, but this was not a significant relationship. Similarly, the higher education of the executives of the projects did not have a significant effect. In our research, the education of the executives was not compatible with their activities, and this incompatibility could be one of the main reasons why the higher education variable was not significant; while the experience of the executives significantly influenced the ability of the projects to pay back the installments. With an increase in the experience of the executives of the projects, the number of outstanding installments declined. Moreover, the applicants residing in the capital city of the province of Mazandaran have significantly more outstanding installments than those living in the eastern and the western parts of the province. As previously mentioned (and can be seen in the results obtained from our research), the number of applicants receiving SME facilities was greater in the capital city of the province; and, hence, it can be concluded that the more the number of loans granted in one geographical area is, the higher the chances that there will be outstanding installments. Although we expected the continuity of the activities of the SMEs to affect the number of SMEs in arrears with their installments, this variable had virtually no significant effect. Credit is one of the most important factors that can affect the performance and success of SMEs. For measuring the effect, we calculated the granted credits per worker in each SMEs. The results of estimation indicate the significance effect of this variable. However, this significance is statistically negative: the less the annual credit is, the more the chances of the success of the SMEs will be, and vice versa. These results can somewhat point to the advantage of the smaller enterprises over 
the larger ones; and also indicate that the more labor- intensive activities enjoy greater success than the less labor- intensive ones.

Table 3. Results of the estimate

\begin{tabular}{llll}
\hline Variable & Coefficients & Standard deviation & Probability \\
\hline constant & -7.18 & 3.22 & 0.0261 \\
Activity kind (dummy) & -5.399 & 1.290 & 0.0000 \\
Age & 0.141 & 0.028 & 0.0000 \\
Experience & 0.014 & 0.0045 & 0.0015 \\
education (dummy) & 1.153 & 1.224 & 0.3465 \\
Credit & -0.015 & 0.0041 & 0.0002 \\
Size (dummy) & 2.091 & 1.402 & 0.1358 \\
Activity continuity (dummy) & 1.019 & 2.575 & 0.6924 \\
Start time (dummy) & -2.691 & 1.361 & 0.0481 \\
Location (dummy) & -2.895 & 1.375 & 0.0353 \\
McFadden goodness of fit & 0.86 & 205.84 & 0.000 \\
\hline
\end{tabular}

Source: Results obtained from the research

\section{Discussion}

The results of the study conducted by Ceranic et al. (2009) on the SMEs in Serbia indicated that the size and the type of the activity of economic enterprises were two the important factors influencing the success of SMEs. In our research, the size of SMEs did not have a significant effect in this respect. In the research carried out by Ceranic et al. (2009) the number of employees in a of SMEs was considered to represent its size, but in our study, it was changed because activity various kinds in selected SMEs. Hassanpour and Aghashiri (2011), in their investigation of 28 poultry farms in the province of Kohkiloyeh and Boirahmad, showed that there was a direct and significant correlation between the level of education of the executives (and of the workers employed) and the level of success of the poultry farms at the $5 \%$ probability level. However, in our research this variable was not significant because the types of education the executives received were not compatible with the SMEs they were in charge of. Therefore, the compatibility of the type of education of the executives with the projects they want to implement can be an effective factor in the success of economic enterprises.

\section{References}

Bilsen, V., \& Konings, J. (1998). Job Creation, Job destruction and growth of newly established, privatized and state owned enterprises in transition economies. Journal of Comparative Economics, 26, 429-445.

Birch, D. (1987). Job Creation in America: How Our Smallest Companies Put The Most People to Work, New York, Free Press.

Broersma, L., \& Gautier, P. (1997). Job creation and job destruction by small firms: an empirical investigation for the Dutch Manufacturing sector. Small Business Economics, 9(4), 211-224.

Ceranic, S. R., Maletic., S., \& Jankovic, Š. (2009). Small and medium size enterprises as support to development of agribusiness of republic of SERBIA. Paper prepared for presentation at the $113^{\text {th }}$ EAAE Seminar. The Role of Knowledge, Innovation and Human Capital in Multifunctional Agriculture and Territorial Rural Development, Belgrade, Republic of Serbia.

Chung, Y. I. (2006). The efficiency of SMEs in the global market: Measuring the Korean performance. Journal of Policy Modeling, 28, 861-876.

Hart, M., \& Hanvey, E. (1995). Job generation and new and small Firms: some evidence from the late 1980s. Small Business Economic, 7, 97-109. 
Hassanpour, B., \& Aghashiri, A. (2011). Study of the factors influencing the failure of some of the broiler farms in the province of Kohkiloyeh and Boirahmad, collected articles presented at the national congress on SMEs (production and employment) in Yassouj in the province of Kohkiloyeh and Boirahmad.

Jamsheedloo, R., Ma-afi Madani, M., \& Rassouli, A. (2011). Recognizing the problems and obstacles of investing in the SMEs of the province of Zanjan and offering implementation strategies (the case study of the city of Abhar), collected articles presented at the national congress on SMEs (production and employment) in Yassouj in the province of Kohkiloyeh and Boirahmad.

Kazemipour, S. (2006). Recent developments and the future of employment and unemployment with an emphasis on the employment situation of Women, the Center for Studies and Research on Populations in Asia and Oceania, 1(1), 20-42.

Rezvani, N. (2011). The importance of bank facilities in increasing employment, collected articles presented at the national congress on SMEs (production and employment) in Yassouj in the province of Kohkiloyeh and Boirahmad.

Storey, D. J. (1994). The ten Percenters, SME Center, University of Warwick.

Wagner, J. (1995). Firm size and job creation in Germany. Small Business Economics, 7(6), 467-474.

Zarenezhad, M., \& Ebrahimi, S. (2011). Study of the deviation of the SMEs in Iran, collected articles presented at the national congress on SMEs (production and employment) in Yassouj in the province of Kohkiloyeh and Boirahmad. The Yearbook of Statistics of Iran, 2007.

Zeraatkeesh, Y., \& Foroughi, W. (2011). Study of the role of the facilities granted to SMEs in job creation and in marketing trout in the province of Kohkiloyeh and Boirahmad, collected articles presented at the national congress on SMEs (production and employment) in Yassouj in the province of Kohkiloyeh and Boirahmad. 